\title{
People can detect poor air quality well below guideline concentrations: a prevalence study of annoyance reactions and air pollution from traffic
}

\author{
Bertil Forsberg, Nils Stjernberg, Stig Wall
}

\begin{abstract}
Objectives-Motor vehicle exhaust fumes are the main source of atmospheric pollution in cities in industrialised countries. They cause respiratory disease and annoy people exposed to them. The relation between ambient exposure to air pollution mainly from motor vehicles and annoyance reactions in a general population was assessed. Also, the importance of factors such as age, sex, respiratory disease, access to the use of a car, and smoking habits on the reporting of these reactions was studied.
\end{abstract}

Methods-A postal questionnaire was sent out in 55 urban areas in Sweden that had nearly identical air quality monitoring stations of the urban air monitoring network. From each area, 150 people aged 16-70 were randomly selected. The questionnaire contained questions on perception of air quality as well as a question on how often exhaust fumes were annoying.

Results-Six-monthly nitrogen dioxide concentrations correlated consistently with the prevalence of reported annoyance related to air pollution and traffic exhaust fumes. Black smoke and sulphur dioxide had no significant effects. The frequency of reporting annoyance reactions was higher among people with asthma, women, and people with lack of access to a car.

Conclusions-In this study town dwellers could detect poor air quality at concentrations well below current guidelines for outdoor air pollution. This suggests that questionnaire studies have a place in monitoring air quality.

Department of

Epidemiology and

Public Health, Umeå

University, Umeå,

Sweden

B Forsberg

$S$ Wall

Department of

Environmental Health,

Umeå University,

Umeå, Sweden

B Forsberg

National Institute of

Occupational Health,

Umeâ, Sweden

N Stjernberg, deceased

Correspondence to:

B Forsberg, Department of

Environmental Health

Umeå University, S-901 87

Umeå, Sweden.

Accepted 29 July 1996
(Occup Environ Med 1997;54:44-48)

Keywords: air pollution; traffic; annoyance

Vehicle exhausts are the main source of air pollution in most cities in industrialised countries. ${ }^{1}$ They may cause respiratory disease, and more often, result in annoyance reactions including physical irritation. Despite the large populations exposed to traffic pollution sufficient to cause irritation, few studies have been published on the quantitative relations between the exposure to traffic pollution and the prevalence of annoyance reactions.

Research in this field was built on social survey techniques and compared mostly qualitatively different environments. ${ }^{2-4}$ We think that many local studies have not been published as general conclusions could not be drawn from them because they lacked objective measurements of air quality. When measured, exposure-response relations could be used for defining guidelines on good air quality and for predictions of benefits from decreased air pollution.

A Swedish study of car exhaust and annoyance showed that people with a negative attitude to traffic, women, and those with symptoms of respiratory sensitivity (such as asthma) are more likely to be annoyed by exhaust fumes. ${ }^{3}$ However, multivariate analysis was not used in this study and women were overrepresented in both the symptomatic risk group and the group with negative attitudes. All factors studied should be analysed simultaneously to avoid confounding, even if only a few factors are studied.

Concentrations of nitrogen dioxide in Swedish towns and cities are highest in winter and result from emissions from motor vehicles and adverse dispersive conditions. However, concentrations are low compared with those reported in studies of health effects. The aim of this study was to assess the relation between a moderate range of concentrations of pollutants in ambient air and the presence of annoyance reactions in a general population. The importance of individual characteristics such as age, sex, presence of respiratory problems, access to a car, and smoking habits was studied as well as air quality.

\section{Methods}

QUESTIONNAIRE INFORMATION

A total of 8250 subjects were randomly selected from among people living in the vicinity of $\mathbf{5 5}$ urban air quality monitoring stations in towns and cities throughout Sweden. From each area 150 subjects aged 16-70 were chosen. However, some had to be excluded because they were found to live outside the chosen areas. Therefore, the total sample population comprised 8060 subjects.

A postal questionnaire was sent early in March 1990 with two reminders sent about two and four weeks later. The questionnaire was presented as a broad study of the local environment, work environment, environmental annoyance, and health. It also included questions on occupation, place of birth, smoking habits, commuting to work or school, access to a car, and household members.

Three questions were concerned with how often the outdoor air during winter in the area 
Table 1 Levels of air pollution and correlations between the three measures of each pollutant ( $n=55$ towns)

\begin{tabular}{|c|c|c|c|}
\hline \multirow[b]{2}{*}{ Indices of air pollution } & \multirow{2}{*}{$\begin{array}{l}\text { Values }\left(\mu g / m^{3}\right) \\
\text { Mean (range) }\end{array}$} & \multicolumn{2}{|c|}{ Correlation coefficients (r) } \\
\hline & & $M M$ & $D M$ \\
\hline \multicolumn{4}{|l|}{ Nitrogen dioxide: } \\
\hline Six monthly average & $19 \cdot 4(32 \cdot 2-9 \cdot 3)$ & $0.94^{\star \star}$ & $0 \cdot 72^{\star \star}$ \\
\hline Monthly maximum & $23 \cdot 6(35 \cdot 5-12 \cdot 8)$ & $1 \cdot 0$ & $0 \cdot 80^{\star \star}$ \\
\hline Daily maximum & $50.9(78.4-26.0)$ & - & \\
\hline \multicolumn{4}{|l|}{ Sulphur dioxide: } \\
\hline Six monthly average & $6 \cdot 4(16 \cdot 0-1 \cdot 7)$ & $0.88^{\star \star}$ & $0 \cdot 87^{\star \star}$ \\
\hline Monthly maximum & $8 \cdot 9(19 \cdot 7-2 \cdot 6)$ & $1 \cdot 0$ & $0.80^{\star \star}$ \\
\hline Daily maximum & $33 \cdot 4(82 \cdot 8-10 \cdot 6)$ & - & $1 \cdot 0$ \\
\hline \multicolumn{4}{|l|}{ Black smoke: } \\
\hline Six monthly average & $9 \cdot 1(16 \cdot 6-4 \cdot 4)$ & $0.93^{\star \star}$ & $0 \cdot 68^{\star \star}$ \\
\hline Monthly maximum & $14 \cdot 3(28 \cdot 6-5 \cdot 5)$ & $1 \cdot 0$ & $0 \cdot 73^{\star \star}$ \\
\hline Daily maximum & $54.9(175 \cdot 1-17 \cdot 8)$ & - & $1 \cdot 0$ \\
\hline
\end{tabular}

$\star \star P$ value $<0.01$.

$\mathrm{MM}=$ monthly maximum; $\mathrm{DM}=$ daily maximum.

where the subjects lived was perceived as being irritant, smelly, and dirty or sooty. Three additional questions dealt with similar aspects of the outdoor air in the town or city centre. One question dealt with how often traffic exhaust fumes where the subjects lived were considered to be annoying. Responses were never or almost never, sometimes or periodically, or daily or almost daily. A response of daily or almost daily was considered to indicate serious annoyance. The response rate was $76 \%$ (6109 out of 8060 ) after the subjects who did not reside at their postal addresses had been excluded.

INFORMATION ON AIR QUALITY

The study areas were selected so that the air quality monitoring station was centrally located. Thus only rarely was any part of the study area more than $700 \mathrm{~m}$ from a station. The Swedish urban air monitoring network is run by the Swedish Environmental Research Institute (IVL) accredited laboratory in collaboration with the local environmental health offices. Locations were chosen so that the results would not be dominated by single sources, and measurements were usually made 5-6 $\mathrm{m}$ above the ground in streets in city centres accessible only to pedestrians, or in open areas without specific sources of pollution. The average daily concentrations of black smoke (modified OECD), sulphur dioxide (impinger method), and nitrogen dioxide (impregnated glass fibre filter) were measured each day from October 1989 to March 1990 (a six month period). Motor vehicles were the main source of air pollution in all areas.

\section{ANALYSIS}

Firstly, a descriptive analysis was made by correlating the prevalences of annoyance related to air pollution with the level of air pollution measured in each town. These data were also inspected with scattergrams. Adjustment for factors other than the level of air pollution was then made with multiple logistic regression based on data from each person. The factors which were included were potential susceptibility factors-age (six categories), sex, and the presence of asthmatic symptoms, and questions related to individual exposure patterns-whether or not the subject had access to a car, if the home was next to an area with a high density of traffic, and the subject's smoking habits (three categories). There was also a question on whether children lived at home. The models included an indicator variable for each town. The estimated $\beta$-coefficients for the towns, which represent the log odds of annoyance, were then analysed by multiple linear regression with the pollution indices as independent variables.

\section{Results}

\section{AIR POLLUTION}

Air pollution at all monitoring stations fell well below the World Health Organisation (WHO) air quality guidelines for Europe and Swedish air quality standards (table 1 ). The mean sixmonthly averages were 19,9 , and $6 \mu \mathrm{g} / \mathrm{m}^{3}$ for nitrogen dioxide, black smoke, and sulphur dioxide, respectively, and the upper quartile limits were 22,10 , and $8 \mu \mathrm{g} / \mathrm{m}^{3}$. The local sixmonthly average for each of the three pollutants correlated strongly with the corresponding monthly $(r=0.88-0.94)$ and daily maximum values $(r=0 \cdot 68-0.87)$. There was also a significant correlation between the six-monthly average nitrogen dioxide and black smoke $(r=0.55, \mathrm{P}<0.01)$.

\section{PREVALENCES AND CORRELATIONS}

Table 2 shows the proportion of subjects expressing daily or almost daily annoyance and the correlation coefficients for these annoyance prevalences with the air pollution measures. No measure of black smoke correlated significantly with any of the annoyance prevalences. Black smoke has therefore not been included in the table.

Table 2 Prevalence of annoyance and correlations with pollutants ( $n=55$ towns)

\begin{tabular}{|c|c|c|c|c|c|c|c|c|}
\hline \multirow[b]{3}{*}{ Annoyance } & \multirow{3}{*}{$\begin{array}{l}\text { Prevalence } \\
(\%) \\
\text { Mean }\end{array}$} & \multirow[b]{3}{*}{ Maximum } & \multicolumn{6}{|c|}{ Correlation coefficients ( $r$ ) } \\
\hline & & & \multicolumn{3}{|c|}{ Sulphur dioxide } & \multicolumn{3}{|c|}{ Nitrogen dioxide } \\
\hline & & & $6-M A$ & $M M$ & $D M$ & $6-M A$ & $M M$ & $D M$ \\
\hline \multicolumn{9}{|l|}{$\begin{array}{l}\text { Outdoor air in the town centre } \\
\text { daily or almost daily: }\end{array}$} \\
\hline Smelly & $8 \cdot 6$ & $28 \cdot 4$ & $0 \cdot 27^{\star}$ & $0 \cdot 26$ & $0 \cdot 30^{\star}$ & $0.54^{\star \star}$ & $0 \cdot 34^{\star}$ & $0 \cdot 44^{\star \star}$ \\
\hline Irritant & $7 \cdot 7$ & $17 \cdot 6$ & $0 \cdot 30$ & $0 \cdot 27^{\star}$ & $0 \cdot 36^{\star}$ & $0.66^{\star \star}$ & $0 \cdot 46^{\star \star}$ & $0 \cdot 58^{\star \star}$ \\
\hline Dirty or sooty & $11 \cdot 5$ & $26 \cdot 5$ & 0.08 & 0.04 & $0 \cdot 21$ & $0.63^{\star \star}$ & $0.50^{\star \star}$ & $0.56^{\star \star}$ \\
\hline \multicolumn{9}{|c|}{$\begin{array}{l}\text { Outdoor air in the residential area } \\
\text { daily or almost daily: }\end{array}$} \\
\hline Smelly & $6 \cdot 1$ & $18 \cdot 1$ & $0 \cdot 25$ & $0 \cdot 30^{\star}$ & $0 \cdot 30^{\star}$ & $0.52^{\star \star}$ & $0 \cdot 36^{\star}$ & $0 \cdot 42^{\star \star}$ \\
\hline Irritant & 4.8 & 13.9 & $0 \cdot 19$ & $0 \cdot 20$ & $0 \cdot 24$ & $0.65^{\star \star}$ & $0 \cdot 46^{\star \star}$ & $0.57^{\star \star}$ \\
\hline Dirty or sooty & $10 \cdot 1$ & $23 \cdot 8$ & 0.01 & -0.01 & $0 \cdot 12$ & $0.58^{\star \star}$ & $0 \cdot 49^{\star \star}$ & $0.53^{\star \star}$ \\
\hline \multicolumn{9}{|l|}{$\begin{array}{l}\text { Annoyed by traffic exhaust } \\
\text { fumes in the residential area }\end{array}$} \\
\hline $\begin{array}{l}\text { fumes in the residentral area } \\
\text { daily or almost daily }\end{array}$ & $16 \cdot 8$ & $34 \cdot 6$ & 0.06 & 0.05 & 0.08 & $0.56^{\star \star}$ & $0 \cdot 34^{\star}$ & $0.52^{\star \star}$ \\
\hline
\end{tabular}

${ }^{\star} \mathrm{P}$ value $<0.05 ;{ }^{\star \star} \mathrm{P}$ value $<0.01$. 6-MA = six-monthly average; $\mathrm{MM}=$ monthly maximum; $\mathrm{DM}=$ daily maximum. 
$A$ plot of the proportion of subjects who reported that they daily or almost daily found the air in the area where they lived to be irritating versus the sixmonthly average nitrogen dioxide concentrations.

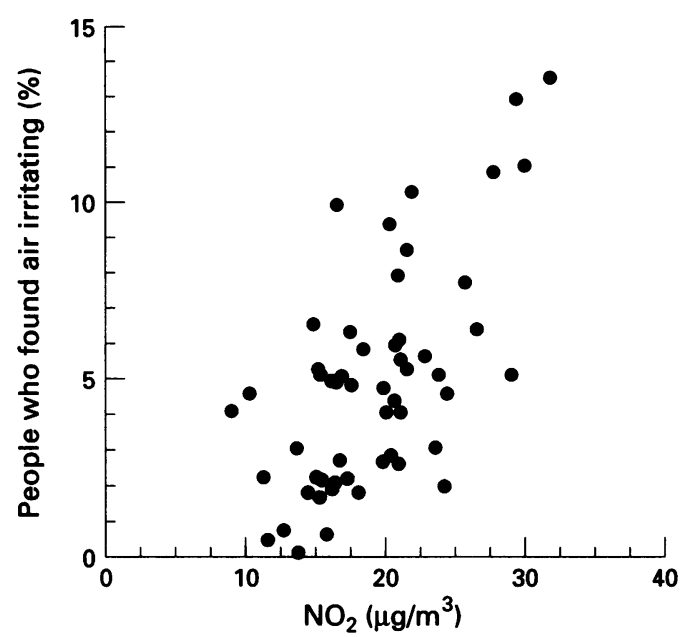

Traffic exhaust fumes where the subjects lived were most often considered to be annoying. The local prevalence ranged from $2 \%$ to $35 \%$ (mean $17 \%$ ).

A greater proportion of subjects were troubled in various ways by the air in the town or city centre than by the air in their residential area. More found the outdoor air frequently dirty or sooty than smelly or irritant. The local prevalences in the city centres ranged from $1 \%$ to $26 \%$ (dirty or sooty), $0 \%$ to $28 \%$ (smelly), and $0 \%$ to $18 \%$ (irritant). The highest prevalences of smells were found in towns with nearby industries, such as pulp mills, that emitted malodorous air pollutants.

The strongest correlations between measures of air pollution and prevalence of annoyed subjects by town or city was found

Table 3 Adjusted regression coefficients for nitrogen dioxide 6-monthly average concentration (95\% CIs) in models for $\log$ odds of annoyance prevalences

\begin{tabular}{ll}
\hline Annoyance & $\beta$-coefficient $(95 \%$ CI) \\
\hline $\begin{array}{l}\text { Outdoor air in the town centre } \\
\text { daily or almost daily: }\end{array}$ & \\
$\quad$ Smelly & $0.23(0.12$ to 0.35$)$ \\
$\quad$ Irritant & $0.20(0.09$ to 0.31$)$ \\
$\begin{array}{l}\text { Dirty or sooty } \\
\text { Outdoor air in the residential }\end{array}$ & $0.17(0.09$ to 0.26$)$ \\
area daily or almost daily: & \\
$\quad \begin{array}{l}\text { Smelly } \\
\text { Irritant }\end{array}$ & $0.18(0.07$ to 0.29$)$ \\
$\begin{array}{l}\text { Dirty or sooty } \\
\text { Annoyed by traffic exhaust fumes } \\
\text { in the residential area } \\
\text { daily or almost daily }\end{array}$ & $0.06(0.04$ to 0.09$)$ \\
\hline
\end{tabular}

Table 4 Adjusted odds ratios with 95\% CIs for the association between perceiving the outdoor air as irritating daily or almost daily in the residential area and the city centre, respectively, and individual characteristics (models also include an indicator variable for each town)

\begin{tabular}{|c|c|c|c|}
\hline Category & $\%$ & $\begin{array}{l}\text { Residential area } \\
\text { Odds ratio }(95 \% \text { CI) }\end{array}$ & $\begin{array}{l}\text { City centre } \\
\text { Odds ratio }(95 \% \text { CI) }\end{array}$ \\
\hline $\begin{array}{l}\text { Age }(y)^{\star}: \\
25-34 \\
35-44 \\
45-54 \\
55-64 \\
65-74 \\
\text { Female } \\
\text { Ex-smokert } \\
\text { Smokerf } \\
\text { Asthma } \\
\text { Children at home } \\
\text { Lack of access to a car } \\
\text { Area with traffic }\end{array}$ & $\begin{array}{r}21 \\
15 \\
18 \\
18 \\
13 \\
52 \\
24 \\
33 \\
8 \\
21 \\
48 \\
69\end{array}$ & $\begin{array}{l}1.0(0.6 \text { to } 1.8) \\
1.6(0.9 \text { to } 2.8) \\
1.2(0.7 \text { to } 2.2) \\
1.3(0.7 \text { to } 2.3) \\
1.5(0.7 \text { to } 2.5) \\
1.5(1.1 \text { to } 2.1) \\
1.0(0.6 \text { to } 1.9) \\
1.1(0.8 \text { to } 1.6) \\
3.9(2.7 \text { to } 5.8) \\
1.1(0.7 \text { to } 1.7) \\
3.3(2.2 \text { to } 4.9) \\
1.2(0.9 \text { to } 1.8)\end{array}$ & $\begin{array}{l}1.5(0.9 \text { to } 2.4) \\
1.9(1.1 \text { to } 3.1) \\
1.7(1.1 \text { to } 2.8) \\
1.5(0.9 \text { to } 2.4) \\
2.1(1.2 \text { to } 3.5) \\
1.4(1.1 \text { to } 1.9) \\
1.0(0.7 \text { to } 1.4) \\
0.9(0.6 \text { to } 1.2) \\
3.6(2.4 \text { to } 4.6) \\
1.2(0.9 \text { to } 1.7) \\
1.9(1.4 \text { to } 2.5) \\
1.4(1.1 \text { to } 1.8)\end{array}$ \\
\hline
\end{tabular}

* $16-24 \mathrm{y}$.

†v Never smoker. between the six-monthly average nitrogen dioxide concentration and the prevalence of subjects who daily or almost daily found the air during winter in the town or city centres $(r=0.66)$ or residential areas $(r=0.65)$ to be irritating. A direct age standardisation with six age classes had little effect on the correlation coefficients; the coefficients for the two correlations already mentioned were 0.64 and $0 \cdot 65$, respectively. The figure shows the plot of the proportions of subjects (age standardised) who reported that they daily or almost daily found the air in the area where they lived irritating against the concentration of nitrogen dioxide at the central monitoring station. There was no indication of a threshold level in the examined plots.

For all annoyance variables, the six-monthly average concentration of nitrogen dioxide gave better correlations than monthly maximum or daily maximum concentrations. A multiple linear regression of annoyance prevalences on the six-monthly averages for concentrations of nitrogen dioxide, sulphur dioxide, and black smoke showed that the annoyance prevalences were significantly related only to the average concentrations of nitrogen dioxide. The age standardised prevalence of reporting outdoor air as being irritating every, or almost every, day in the town or city centres and the residential areas respectively, gave regression coefficients of $0.64(95 \% \mathrm{CI} 0.39-0.88)$ and 0.43 (95\% CI 0.28-0.59) for nitrogen dioxide concentrations.

ADJUSTED ASSOCIATIONS WITH AIR POLLUTION When the $\beta$-coefficients for the towns from the logistic regression were analysed with multiple linear regression, only nitrogen dioxide was a significant determinant, and the results were consistent in all seven models (table 3 ). The non-significant relations with sulphur dioxide and black smoke are not shown. The association with nitrogen dioxide was greater for the annoyance questions which dealt with different aspects of air pollution in the town or city centre than it was for questions on the outdoor air in the area in which the subject lived. The effect was strongest for reporting the outdoor air in the city or town centre as smelly or irritant. When the analyses were stratified for sex, there were some differences in the coefficients between men and women, but they were not consistent for the different annoyance variables.

\section{INDIVIDUAL DETERMINANTS}

The importance of individual characteristics was found in the logistic regression models. The results were similar for the different annoyance variables. Table 4 shows the results for the questions on the outdoor air being irritating. The frequency of reporting that the air was irritating was lowest in the youngest group, aged 16-24 years. Otherwise there was no age related trend. Women showed a significantly higher prevalence than men, the odds ratios being 1.4 and 1.5 for the two questions respectively.

Asthma, which was reported by $8 \%$ of the 
respondents, was a strong risk factor, with odds ratios of 3.6 and 3.9 , respectively for the two questions. Lack of access to a car was also a significant risk factor, but living in a home in an area of heavy traffic was a significant risk only in the model for the air in the town or city centre. Smoking habits and children living at home were not significant risk factors for reporting that the outdoor air was irritating.

\section{Discussion}

When asked in what manner subjects found the outdoor air annoying, more people considered that the air was more often dirty or sooty than smelly or irritant. Similar results were reported from London, UK, and the authors suggest that smoke and concentrations of total suspended particles may be better indicators of the nuisance effect than other measures of pollutants. ${ }^{4}$ In 21 highly polluted census tracts in Birmingham, Alabama, ${ }^{5}$ dustfall had a more significant association with public opinion about air pollution $(r=0.80)$ than total suspended particles $(r=0.54)$ or average concentrations of nitrogen dioxide, which were not significantly correlated with the public opinion. A review of British surveys of the public's response to traffic pollution carried out in the 1970s also found that the public were most concerned about dirt and soiling associated with road traffic. ${ }^{2}$ In this study more people found the outdoor air dirty or sooty than smelly or irritant. However, we found that the local prevalence of annoyance related to air pollution in 55 Swedish towns and cities did not correlate significantly with black smoke. The best correlations were found with long term concentrations of nitrogen dioxide.

Multivariate analyses showed that only nitrogen dioxide was significant when sulphur dioxide and black smoke were also included in the models. Our results show this doseresponse relation for annoyance reactions in town or city centres at mean six-monthly winter half yearly concentrations of nitrogen dioxide below $33 \mu \mathrm{g} / \mathrm{m}^{3}$. The current Swedish air quality standard for the six-monthly average concentration of nitrogen dioxide is $50 \mu \mathrm{g} / \mathrm{m}^{3}$. The concentration of nitrogen dioxide at the monitoring station may in this situation be regarded as an indicator of the population's average exposure to air pollution related to vehicle exhaust fumes which makes generalisations easier than results based on the often used variants of traffic flow within certain distances. ${ }^{6-8}$

Information about the quantitative relation between measured air quality and annoyance reactions related to air pollution has been lacking, although the importance of individual factors related to the reporting of annoyance in different situations has been described. ${ }^{9}$

In epidemiological studies of acute respiratory effects of short term variations in air pollution, people with asthma have been shown to be a susceptible group but whether or not this is due to nitrogen dioxide has not been conclusively proved. ${ }^{1011}$ Human chamber studies have generally shown effects on pulmonary function only at concentrations of nitrogen dioxide much higher than those reported in epidemiological studies. Particles, together with sulphur dioxide and ozone, are the most obvious pollutants that worsen asthma, but in Nordic countries where traffic is the major source of pollution, nitrogen dioxide has correlated significantly with hospital visits for asthma, ${ }^{12}$ pulmonary function in people with asthma ${ }^{13}$ and the prevalence of general symptoms. ${ }^{14}$ Our results confirm that subjects with symptoms of asthma more often perceive the outdoor air as irritating. Lack of access to a car resulted in higher odds ratios. This could mean that people forced to travel by walking from home, perceive more the annoyance from pollutants in the vicinity of their homes. Their attitudes toward traffic pollution may also be different from those who own cars.

In an earlier study Swedish women were more annoyed than men by vehicle exhausts. ${ }^{3}$ Also in this study adjusted odds ratios for women were higher than for men. It is possible that non-measured acquired attributes associated with sex explain at least parts of the difference between the sexes that remained after our adjustment. Women have been shown to be more environmentally concerned than men ${ }^{1516}$ and this might affect awareness and reporting. However, in a recent study after a clinical examination the typical sex differences in reporting sick building symptoms could not be explained by women overreporting symptoms. ${ }^{17}$

In this large study of 55 samples from all over Sweden, adjustment for various potential confounding factors at the individual level did not change the overall conclusion that the concentration of nitrogen dioxide is an important predictor of annoyance reactions, in spite of several individual characteristics being significant risk factors. The effects of adjustments for confounders may, however, differ from study to study depending on the populations included. As in all studies of ecological exposure variables, there may be uncontrolled confounders of an ecological nature. As nitrogen dioxide is predominantly generated locally from motor vehicles in these cities, other traffic related pollutants may contribute to the associations we found. Our results show that people can detect poor air quality related to motor vehicles at long term concentrations well below current guidelines, when assessed from a postal questionnaire. This suggests that questionnaire studies have a place in monitoring air quality, and that improvements in air quality will reduce the number of annoyed people.

This study was supported by the Centre for Environmental Research (CMF) in Umea and the Swedish Environmental Research Institute.

1 World Health Organization, United Nations environment programme. Urban air pollution in megacities of the world. .

2 Ball DJ, Caswell R. Smoke from diesel-engined road vehicles: an investigation into the basis of British and European emission standards. Atmos Environ 1983;17: 169-81.

3 Ewetz L, Camner P, eds. Health risks resulting from exposure to motor vehicle exhaust. Stockholm: National Swedish Institute of Environmental Medicine, 1983. 
4 McCrae IC, Williams ID. Road traffic pollution and public nuisance. Sci Total Environ 1994;146/147:81-91.

5 Stalker WW, Robison CB. A method for using air pollution measurements and public opinion to establish ambient measurements and public opinion to establish ambient
air quality standards. fournal of Air Pollution Control air quality standards. Fou

6 Nitta H, Sato T, Nakai S, Maeda K, Aoki S, Ono M. Respiratory health associated with exposure to automobile exhaust. I. Results of cross-sectional studies in 1979 1982, and 1983. Arch Environ Health 1993;48:53-8.

7 Wjst M, Reitmeir P, Dold S, Wulff A, Nicolai T, Loeffelholz-Colberg EF, Mutius E. Road traffic and adverse effects on respiratory health in children. $B M \mathcal{F}$ 1993;307:596-600

8 Edwards J, Walters S, Griffiths RK. Hospital admissions for asthma in pre-school children: relationship to major roads in Birmingham, United Kingdom. Arch Environ Health 1994;49:223-7.

9 Evans GW, Colome SD, Shearer DF. Psychological reactions to air pollutions. Environ Res 1988;45:1-5.

10 Samet JM, Utell MJ. The risk of nitrogen dioxide: what have we learned from epidemiological and clinical studies? Toxicol Ind Health 1990;6:247-62.
11 Berglund M, Boström C-E, Bylin G, Ewetz L, Gustavsson $\mathrm{L}$, Moldeus $\mathrm{P}$, et al. Health risk evaluation of nitrogen oxides. Scand $\mathcal{f}$ Work Environ Health 1993;19(suppl 2: 1-720).

12 Rossi OVJ, Kinnula V, Tienari J, Huhti E. Association of severe asthma attacks with weather, pollen, and air pollutants. Thorax 1993;48:244-8.

13 Moseholm L, Tandorf E, Frosig A. Pulmonary function changes in asthmatics associated with low-level $\mathrm{SO}_{2}$ and $\mathrm{NO}_{2}$ air pollution, weather, and medicine intake. Allergy 1993;48:334-44.

14 Clench-Aas J, Larssen S, Bartonova A, Aarnes MJ, Myhre $\mathrm{K}$, Christensen CC, et al. The health effects of traffic pollution as measured in the Valleberga area of Oslo-summary report.

15 McStay JR, Dunlap RE. Male-female differences in concern for environmental quality. International fournal of Women's Studies 1983;6:291-301.

16 Howe HL. Predicting public concern regarding toxic substances in the environment. Environ Health Perspect stances in the

17 Stenberg B, Wall S. Why do women report sick building symptoms more than men? Soc Sci Med 1995;40:491-502.

\section{Vancouver style}

All manuscripts submitted to Occup Environ Med should conform to the uniform requirements for manuscripts submitted to biomedical journals (known as the Vancouver style.)

Occup Environ Med, together with many other international biomedical journals, has agreed to accept articles prepared in accordance with the Vancouver style. The style (described in full in the BMF, 24 February $1979, p$ 532) is intended to standardise requirements for authors.

References should be numbered consecutively in the order in which they are first mentioned in the text by Arabic numerals above the line on each occasion the reference is cited (Manson ${ }^{1}$ confirmed other reports $^{2-5} \ldots$. .). In future references to papers submitted to Occup Environ Med should include: the names of all authors if there are seven or less or, if there are more, the first six followed by et al; the title of journal articles or book chapters; the titles of journals abbreviated according to the style of Index Medicus; and the first and final page numbers of the article or chapter. Titles not in Index Medicus should be given in full.

Examples of common forms of references are:

1 International Steering Committee of Medical Editors, Uniform requirements for manuscripts submitted to biomedical journals. $B M \Im$ 1979;1:532-5.

2 Soter NA, Wasserman SI, Austen KF. Cold urticaria: release into the circulation of histamine and eosinophil chemotactic factor of anaphylaxis during cold challenge. N Engl F Med 1976;294:687-90.

3 Weinstein L, Swartz MN. Pathogenic properties of invading micro-organisms. In: Sodeman WA Jr, Sodeman WA, eds. Pathologic physiology, mechanisms of disease. Philadelphia: W B Saunders, 1974:457-72. 